\title{
Perancangan Sistem Informasi Penjualan Pada Toko Udin Makasar Berbasis Java
}

\author{
Rifhal Adriansyah ${ }^{1}$, Juliana ${ }^{2}$, Luh Putu Widya Adnyani ${ }^{3}$ \\ ${ }^{1}$ Teknik Informatika, Universitas Indraprasta PGRI \\ ${ }^{2}$ Teknik Informatika, Universitas Indraprasta PGRI \\ ${ }^{3}$ Teknik Informatika, Universitas Indraprasta PGRI \\ ${ }^{1}$ kangrifhal@gmail.com
}

\begin{abstract}
The purpose of this research is to simplify the tasks of employees and assist in the recording of reports addressed to udin makasar store owners so that they can be done effectively. At this time all types of transactions in udin makasar store are still done manually, such as purchase transactions from suppliers and sales transactions to customers, stock of goods that have not been recorded so that if employees want to know the existing stock of goods employees must check directly at the storage of goods. Waiting times occur when purchasing transactions to check availability and also prices that happen to not be displayed computerized at the store. So from the problems that arise the authors hope that with this application sales transactions in stores that are still manual to be computerized so that the process becomes more effective and efficient. Researchers also conducted research using the Rapid Application Development (RAD) method, which is a linear sequential software development process that prioritizes the process development cycle in a short time, RAD Model is a method development of the waterfall model. After testing the researchers concluded that the sales application based on computer systems can be effectively and efficiently in the process of presenting data that is fast and accurate, this sales system was created with the support of the programming language Java Netbeans 8 and XAMPP as datastore media.
\end{abstract}

Keywords: design, information systems, seller, store, java.

\begin{abstract}
Abstrak
Tujuan dari penelitian ini adalah untuk mempermudah tugas karyawan dan membantu dalam pencatatan laporan yang ditujukan kepada pemilik toko udin makasar sehingga dapat dikerjakan secara efektif. Pada saat ini semua jenis transaksi di toko udin makasar masih dilakukan secara manual, seperti transaksi pembelian dari supplier dan transaksi penjualan terhadap pelanggan, stok barang yang belum dilakukan pendataan sehingga apabila pegawai ingin mengetahui stok barang yang ada pegawai harus mengecek langsung di tempat penyimpanan barang. Terjadinya waktu tunggu ketika transaksi pembelian untuk mengecek ketersediaan dan juga harga yang kebetulan tidak ditampilkan secara komputerisasi di toko. Maka dari masalah yang timbul penulis berharap dengan adanya aplikasi ini transaksi penjualan di toko yang masih manual menjadi terkomputerisasi sehingga proses menjadi lebih efektif dan efisien. Peneliti juga melakukan penelitian menggunakan metode Rapid Application Development (RAD) yaitu sebuah proses perkembangan software sekuensial linier yang mengutamakan siklus perkembangan proses dalam waktu yang singkat, Model RAD adalah suatu perkembangan metode dari model waterfall. Setelah dilakukan pengujian peneliti menyimpulkan bahwa aplikasi penjualan berbasis sistem komputer dapat secara efektif dan efisien dalam melakukan proses penyajian data yang cepat dan akurat, Sistem penjualan ini tercipta dengan dukungan bahasa pemrograman Java Netbeans 8 dan XAMPP sebagai media datastore.
\end{abstract}

Kata kunci: perancangan, sistem informasi, penjualan, toko, java.

\section{Pendahuluan}

Seiring dengan perkembangan teknologi, kemajuan komputer yang kian bertambah pesat terutama di bidang komputer. Komputer saat ini tidak hanya menjadi sebuah media pengajaran tetapi juga menjadi suatu ilmu baru yang sangat berguna bagi perkembangan dunia teknologi informasi dan manusia sebagai penggunanya. Dengan pemanfaatan dan penerapan teknologi informasi, kumpulan data yang saling berhubungan satu Berdasarkan latar belakang masalah yang sudah sama lain dapat diorganisasikan menjadi sebuah file, di diuraikan diatas, permasalahan dapat dirumuskan yaitu mana data diorganisasikan kemudian disimpan ke dalam Toko Udin Makasar belum memiliki sistem yang komputer untuk memudahkan pemakai dalam terkomputerisasi, tidak adanya pencatatan stok barang, mengakses data [1]. Namun pemanfaatan teknologi ini tidak memiliki laporan penjualan yang akurat karena 
proses penjualan masih manual. Penelitian yang terstruktur dan mempersingkat waktu antara dilakukan di toko udin makasar bertujuan untuk perancangan dan penerapan sistem [4]. Untuk mengumpulkan data seakurat mungkin agar dapat mendapatkan hasil yang maksimal dalam penelitian ini, merancang sebuah sistem informasi penjualan pada toko peneliti membuat langkah-langkah yang digunakan udin makasar, untuk mempermudah tugas karyawan sesuai metode RAD untuk rancang bangun aplikasi toko dalam pengolahan data agar tidak terjadi kesalahan, penjualan pada toko udin makasar yaitu sebagai berikut: membuat sistem informasi yang efektif dan juga efisien sesuai dengan kebutuhan pada toko udin makasar, membuat laporan dengan cara memanggil datastore dari setiap proses pada tanggal dan bulan yang telah ditentukan. Kegunaan penelitian ini diharapkan dapat memberikan manfaat yang baik bagi pihak-pihak yang terkait diantaranya peneliti membangun aplikasi penjualan agar mempermudah kinerja karyawan toko, serta membuat laporan yang lebih efektif agar data yang telah tersimpan dapat diserahkan kepada pemilik toko, menambah wawasan serta menerapkan ilmu yang telah didapat selama perkuliahan dengan merancang sistem informasi penjualan pada toko udin makasar berbasis java.

\section{Metode Penelitian}

Penelitian ini dilaksanakan di Toko Udin Makasar, Jakarta Selatan. Penelitian dilakukan dalam rangka pembangunan system informasi penjualan pada toko udin makasar. Metode penelitian yang digunakan dalam penelitian ini adalah metode Rapid Application Development (RAD) di mana metode ini memiliki kelebihan yang mengutamakan siklus perkembangan proses dengan mempersingkat waktu pengerjaan aplikasi dan proses agar segera dapat memperdayakan sistem perangkat tersebut secara tepat dan cepat [2]. Adapun metode penelitian ini dilakukan untuk merancang sistem informasi terkait adalah:

Pengamatan (Observasi) dilakukan dengan cara meneliti langsung toko udin makasar untuk memperoleh dan mengumpulkan data yang dibutuhkan mengenai proses penjualan pada toko.

Wawancara (Interview) dilakukan dengan cara tanya jawab terhadap pemilik toko yang dianggap sebagai sumber informasi tentang toko yang sedang diamati.

Kepustakaan (Library Research) dilakukan menggunakan buku-buku, teori dan jurnal yang berhubungan dengan topik dan masalah dalam penelitian ini.

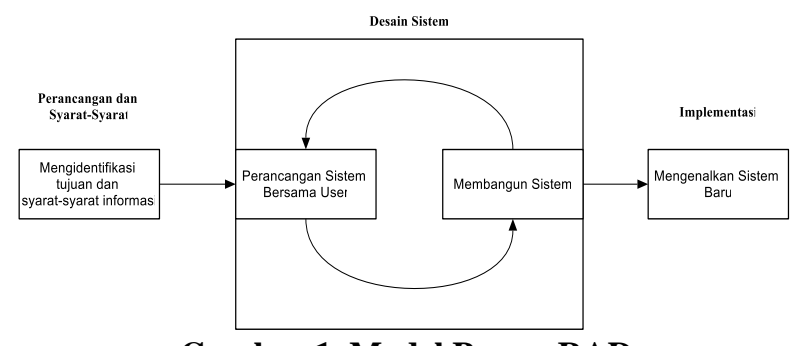

Gambar 1. Model Proses RAD

\subsection{Requirements Planning (Tahap Perencanaan Kebutuhan)}

Untuk menghasilkan sistem informasi tersebut maka dapat dijabarkan beberapa rencana kebutuhan sebagai berikut:

Kebutuhan Hardware

1) Notebook dengan Proccesor AMD Radeon 1.5 $\mathrm{GHz}$.

2) Memory 2 GB dan 320 GB HDD.

3) Printer Canon PIXMA TS307.

Kebutuhan Software

1) Sistem operasi windows 10 .

2) Microsoft Office Word, Visio, Access, Excel 2013.

3) Netbeans IDE 8.2.

4) Database Mysql, Xampp.

Kebutuhan Input

1) Data Barang.

2) Data Supplier.

3) Data Penjualan.

Kebutuhan Informasi

1) Laporan data barang.

2) Laporan data barang rusak.

3) Laporan penjualan.

Model RAD dengan Requirement Planning, Design dan Implementation Metode RAD sangat mementingkan keterlibatan user dalam proses analisis dan perancangannya sehingga dapat memenuhi kebutuhan user dengan baik dan secara nyata akan dapat meningkatkan tingkat kepuasan pengguna sistem keseluruhan [3].

\section{Hasil dan Pembahasan} Dalam pengembangan sistem informasi penjualan ini tahap login ke aplikasi dan langsung ke menu utama dan

menggunakan metode RAD. Pada proses RAD ini melakukan pengolahan data barang, data supplier dan bertujuan agar pengembangan sistem ini lebih

\subsection{Design System (Tahap Desain Sistem)}

Tahap desain dapat dilihat dengan desain arsitektur penggunaan aplikasi. Dimulai dengan admin melalui

User interface (antar muka) untuk mengoperasikan sistem informasi penjualan toko pada toko udin makasar yaitu keybord dan mouse. Secara fisik, antarmuka user yang dirancang adalah tampilan layar menu pilihan administrator, from isian dan laporan terkait dengan data yang diolah yaitu data barang, data supplier dan data penjualan [5]. 
data penjualan [6]. Dan dapat dilihat dalam perancangan antar muka seperti gambar di bawah ini.

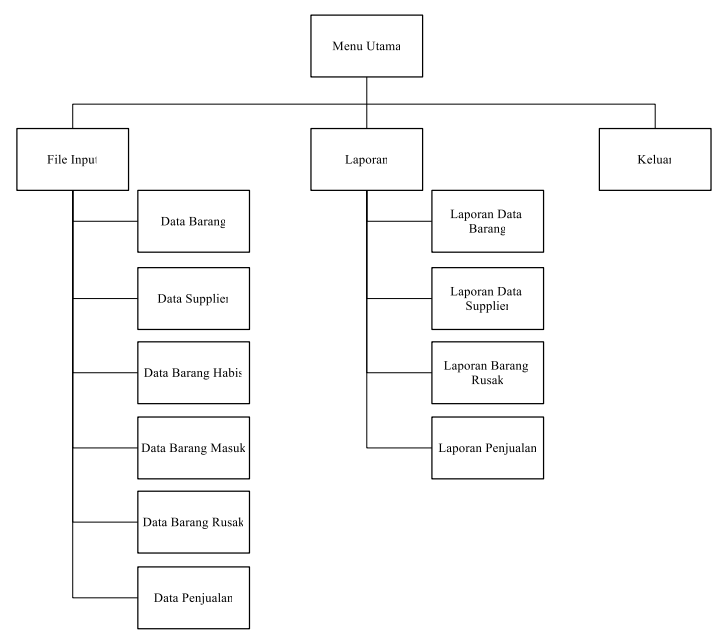

Gambar 1. Antar Muka Pengguna

Dalam tahap ini user berkontribusi untuk merancang program tampilan agar memenuhi kebutuhan dan kepuasan user dalam menjalankan program tersebut [7]. Desain berikutnya dapat dilihat dalam bentuk context diagram, data flow diagram (dfd) level 0 serta entity relationship diagram yang sudah dengan persetujuan pemilik toko udin makasar.

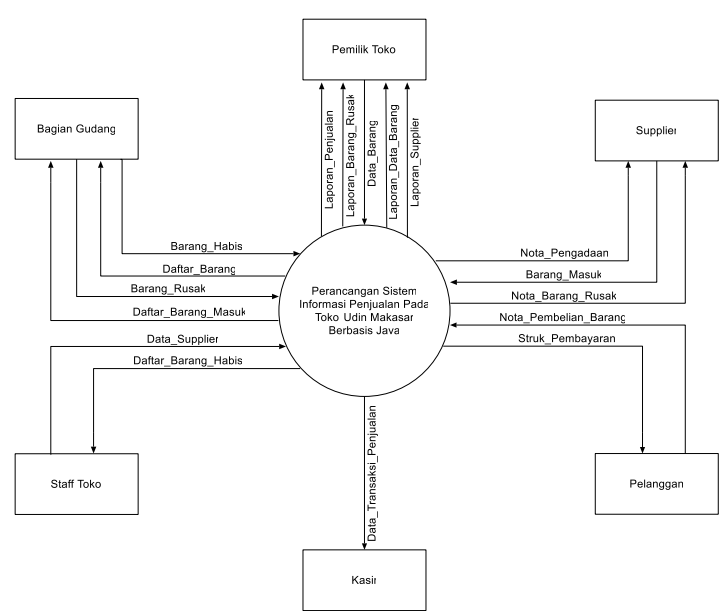

Gambar 2. Context Diagram

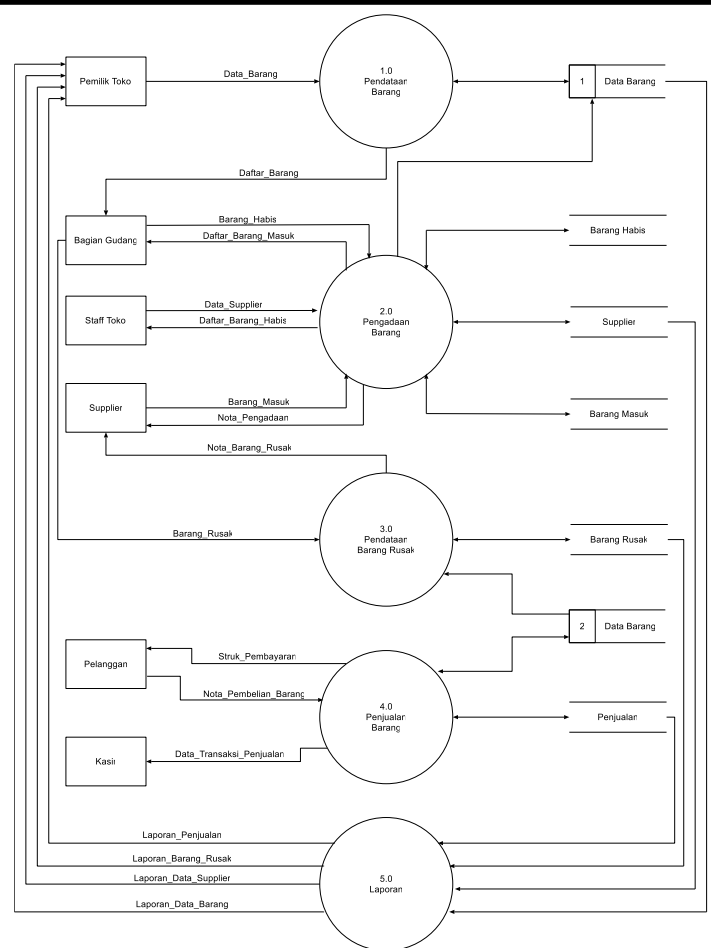

Gambar 3. DFD Level 0

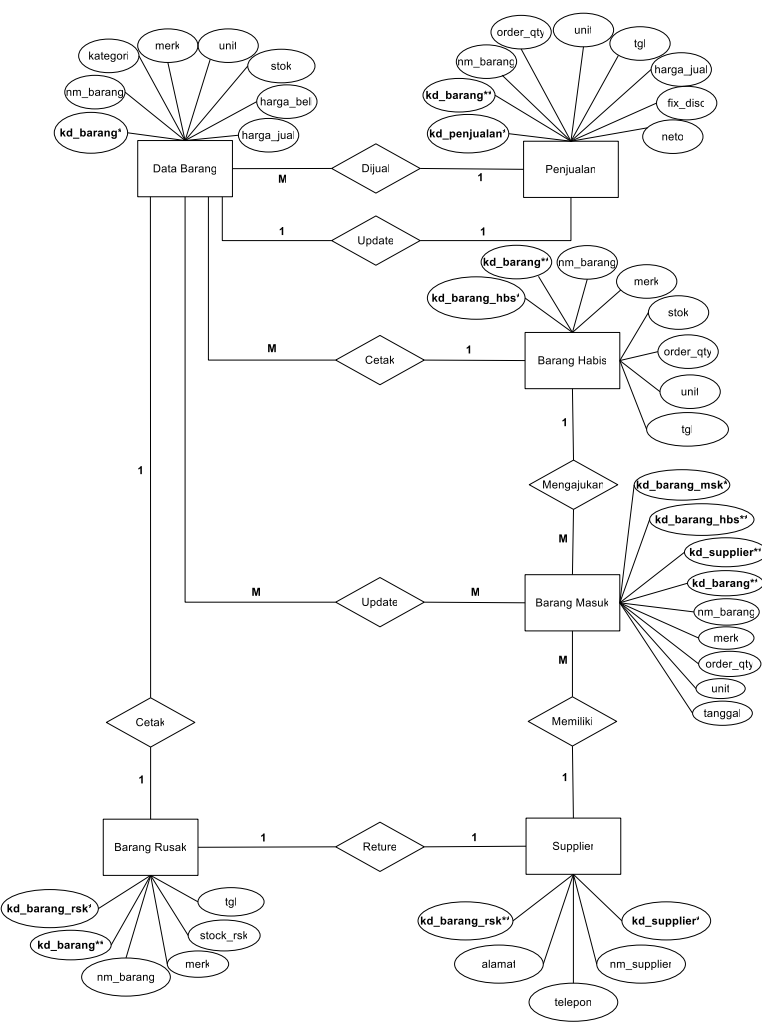

Gambar 4. Entity Relationship Diagram

Model ERD berisi komponen-komponen entitas dan himpunan relasi yang masing- masing dilengkapi dengan atribut-atribut yang mempresentasikan seluruh fakta yang ditinjau sehingga dapat diketahui hubungan antara entity-entity yang ada dengan atribut- atributnya [8]. Selain itu juga bisa menggambarkan hubungan yang ada dalam pengolahan data, seperti hubungan many to 
many, one to many, one to one. Berikut simbolsimbol[10]

\subsection{Implementation (Tahap Implementasi)}

Dalam tahap ini dapat dilihat dengan melakukan pengujian sistem informasi pada proses yang dibuat. Pengujian sistem ini dapat ditunjukan dengan gambar hasil dari sistem yang telah dibuat seperti dibawah ini:

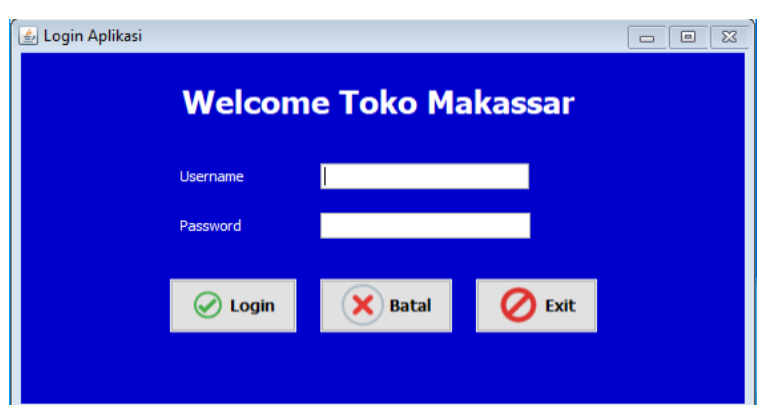

Gambar 5. Tampilan Login

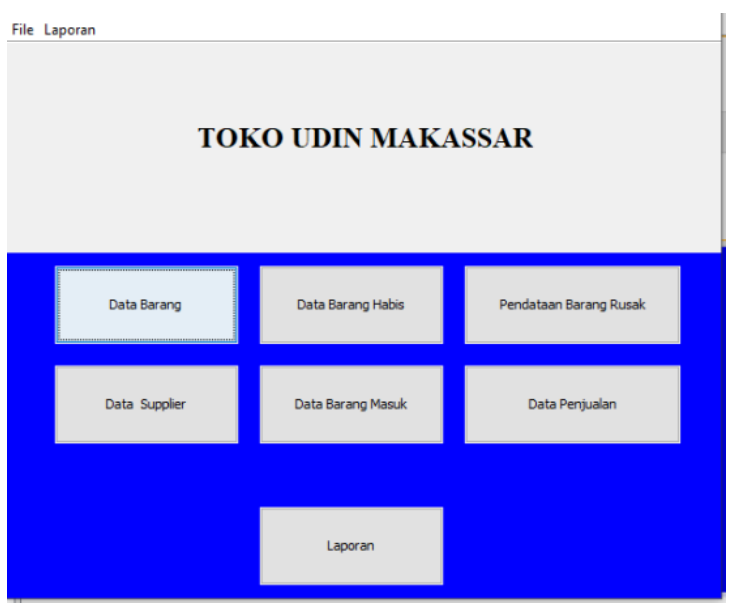

Gambar 6. Tampilan Menu Utama

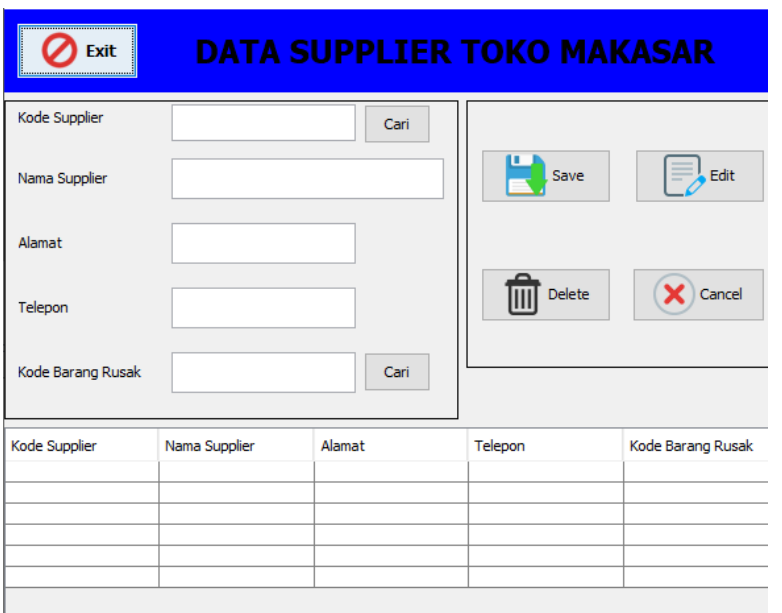

Gambar 7. Tampilan Form Data Supplier

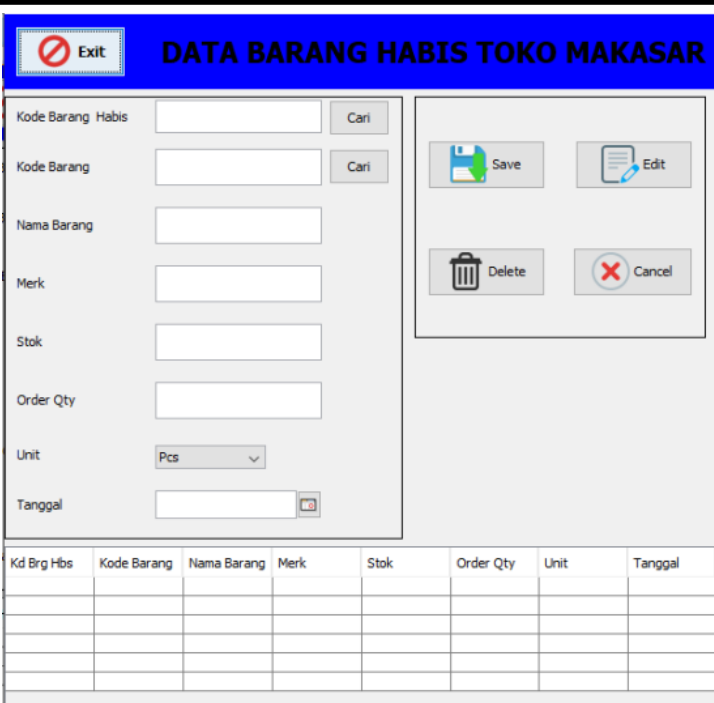

Gambar 8. Tampilan Form Barang Habis

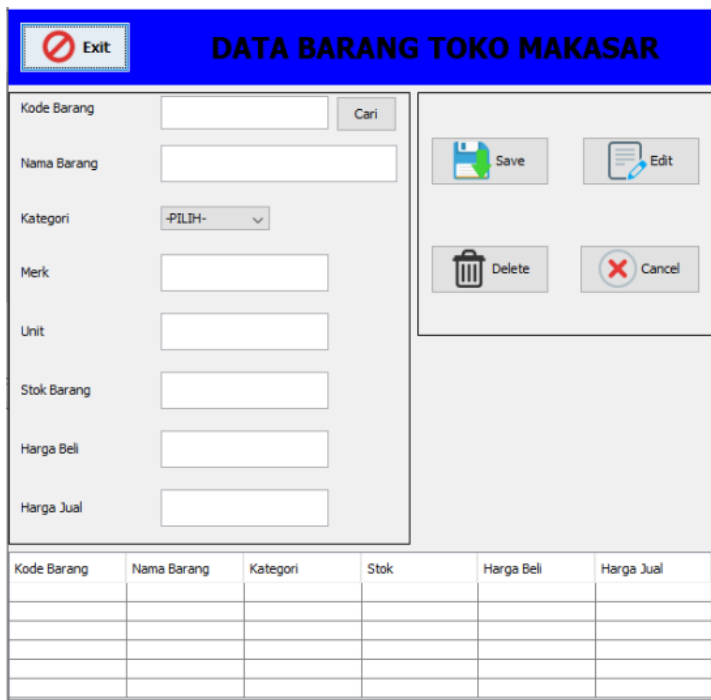

Gambar 9. Tampilan Form Data Barang

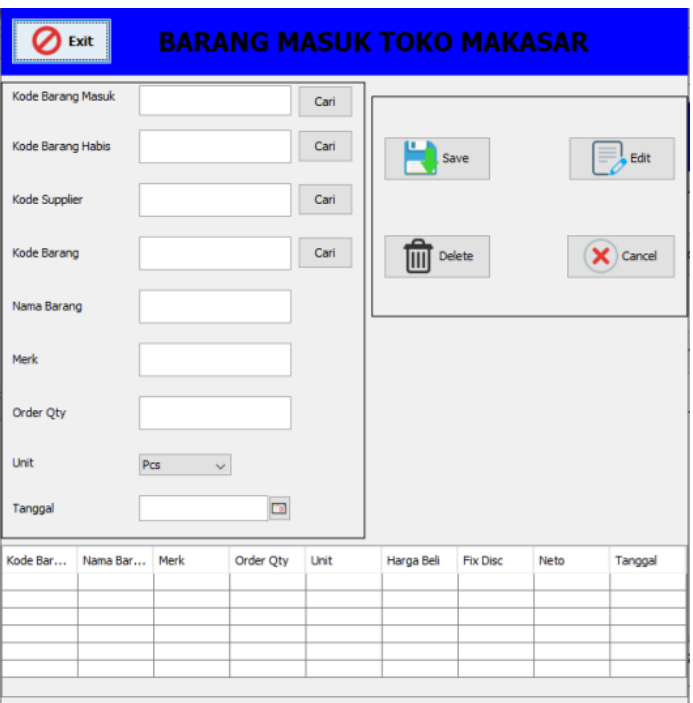

Gambar 10. Tampilan Form Barang Masuk 


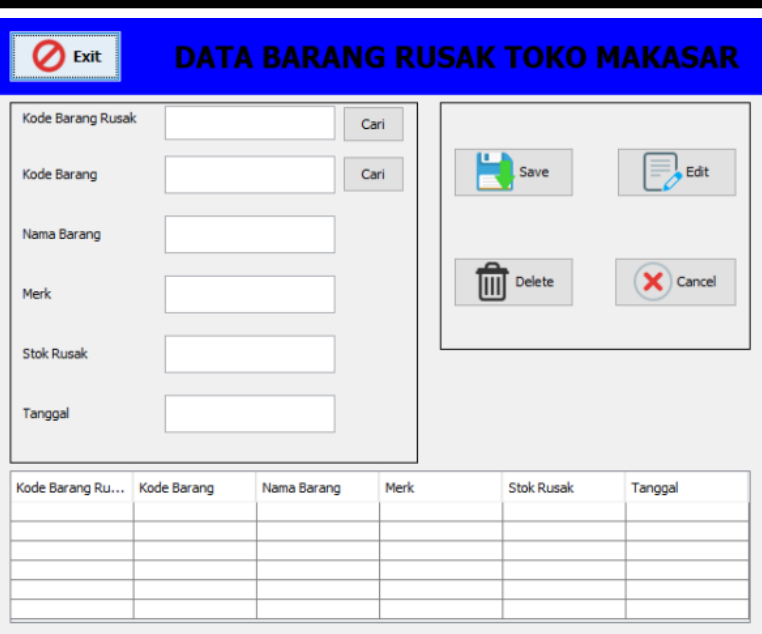

Gambar 11. Tampilan Form Data Barang Rusak

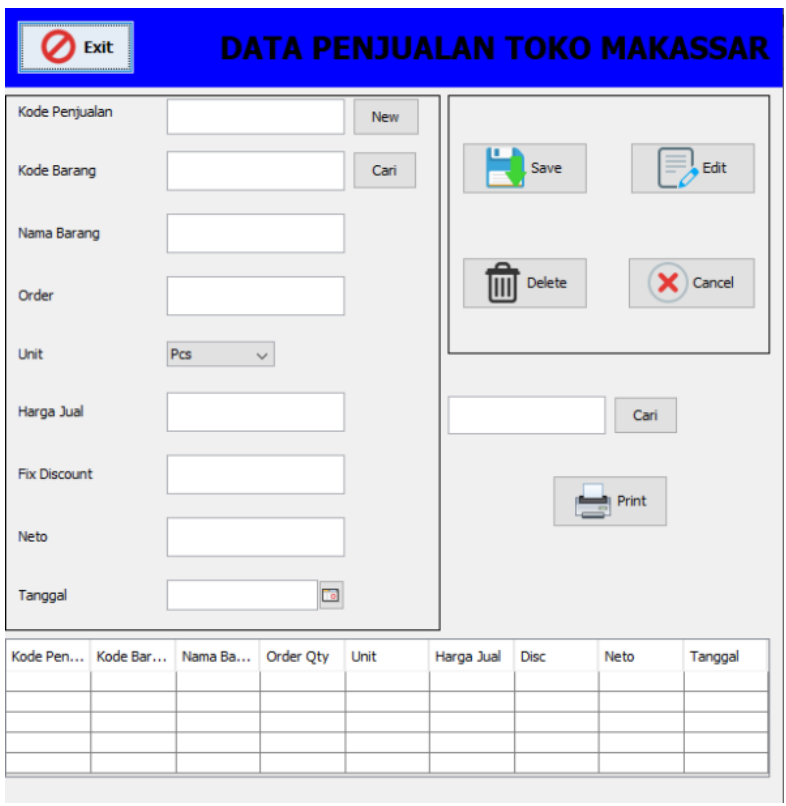

Gambar 12. Tampilan Form Data Penjualan

\section{Kesimpulan}

Sistem informasi yang penulis buat, akan dapat membantu karyawan dalam melakukan pekerjaan mereka, dapat mengurangi risiko kehilangan data karena proses pendataan sudah tersimpan didalam database, dan sistem penjualan pada toko sudah dapat menangani pengolahan data penjualan, menjadikan laporan lebih akurat sehingga dapat memberikan informasi total poin penjualan yang dilakukan karyawan. Dengan diterapkannya aplikasi penjualan pada toko udin makasar berbasis java merupakan langkah maju dalam penerapan teknologi informasi, rancang bangun aplikasi yang peneliti buat sebagai bantuan untuk pemilik toko udin makasar agar lebih efektif dan efisien dalam proses pendataan dan transaksi barang yang dilakukan pembeli (customer).

Sejalan dengan aplikasi yang telah dibuat, maka dengan tercapainya tujuan dan saran yang diperlukan adanya perbaikan tambahan terhadap aplikasi ini antara lain adalah menambahkan metode pemilihan transaksi agar lebih mudah saat pembayaran, sistem informasi penjualan pada toko udin makasar masih memerlukan pengembangan dan modifikasi agar lebih menarik dan lebih mudah dalam penggunaan dan pengembangannya.

\section{Daftar Rujukan}

[1] M. Ferdika and H. Kuswara, "Sistem Informasi Penjualan Berbasis Web Pada PT Era Makmur Cahaya Damai Bekasi," Inf. Syst. Educ. Prof. E-ISSN 2548-3587, vol. 1, no. 2, pp. 175-188, 2017

[2] S. Aswati and Y. Siagian, "Model Rapid Application Development Dalam Rancang Bangun Sistem Informasi Pemasaran Rumah (Studi Kasus : Perum Perumnas Cabang Medan," Sesindo, pp. 317-324, 2016.

[3] A. Firman, H. F. Wowor, X. Najoan, J. Teknik, E. Fakultas, and T. Unsrat, "Sistem Informasi Perpustakaan Online Berbasis Web," E-Journal Tek. Elektro Dan Komput., vol. 5, no. 2, pp. 29-36, 2016.

[4] K. H. dan A. S. Riandya, "Rancang Bangun Sistem Informasi Penjualan Barang (Studi Kasus: U.D1. Riandya KH dan AS. Rancang Bangun Sistem Informasi Penjualan Barang (Studi Kasus: U.D Cendana Depok Townsquare). J Sist Inf [Internet]. 2012;4(1):1-6, 2012.

[5] J. Barong, K. Unmul, G. Kelua, S. Samarinda, and F. Pseudocode, "Memahami Penggunaan Diagram Arus Data Haviluddin," J. Inform. Mulawarman, vol. 4, no. 3, 2009.

[6] A. P. Sudarmadji, F. Teknologi, and D. A. N. Informatika, PERSEDIAAN BAHAN BAKU BERBASIS WEB PADA CV. 2017.

[7] Kosasi, Sandy, "Penerapan Rapid Application Development Dalam Sistem Perniagaan Elektronik Furniture", Citec Journal, Vol. 2 No. 4, Agustus-Oktober 2015, ISSN 24604259 .

[8] Jogiyanto. (2017). Konsep Dasar Sistem Informasi. Konsep Dasar Sistem Informasi.

[9] Romney, M. B., \& Steinbart, P. J. (2015). Pengertian sistem menurut Marshall B Romney dan Paul John Steinbart. In Sistem Informasi Akuntansi.

[10] Wijaya, K. M. (2016). Pengertian CD (Context Diagram) dan DFD (Data Flow Diagram). 